\title{
ANALISIS ZAT WARNA TARTRAZIN PADA JAJANAN MINUMAN RINGAN TAK BERLABEL YANG DIJUAL PEDAGANG KAKI LIMA DI BANDA ACEH
}

\author{
Bhayu Gita Bhernama \\ Prodi Kimia Fakultas Sains dan Teknologi Uin Ar-raniry Banda Aceh \\ Email: deta.chavez1678@gmail.com
}

\begin{abstract}
Analysis of Tartrazine dye on unlabeled soft drinks which is sold of hawkers in Banda Aceh has been done. The dye Tartrazine is a synthetic dye that is used by people as a food additive (BTP) to increase the attractivenes of drinks. This analysis aims are to determine whether it content of tartrazine dye or not and to determine the amount of Tartrazine dye in each unlabeled soft drinks. The results of the analysis were found the value of dye Tartrazine at a wavelength of 427 $\mathrm{nm}$ around 1,06457- $40.6126 \mathrm{mg} / \mathrm{L}$ Based on the ADI (Acceptable Daily Intake) is about $7.5 \mathrm{mg}$ / Kg / day Tartrazine levels exceed a predetermined limit. KBPOM No. 37 In 2013 the maximum limit stipulated that the use of BTP coloring dye tartrazine which allowed the $70 \mathrm{mg} /$ $\mathrm{Kg}$.
\end{abstract}

Keywords: Tartrazine, Paper Chromatography, Spectrofotometry UV/vis

\section{PENDAHULUAN}

Dewasa ini, semakin berkembangnya ilmu pengetahuan dan teknologi menyebabkan perubahan yang sangat besar terhadap pola hidup masyarakat terutama dalam memenuhi kebutuhan asupan gizi serta pengolahan makanan dan minuman. Perubahan pola hidup dalam memenuhi kebutuhan gizi salah satunya adalah kebiasaan jajan. Jajanan menjadi bagian yang tidak dapat dipisahkan dalam kehidupan masyarakat yang kontenporer saat ini, disebabkan karena murah, mudah didapat, cita rasa yang sesuai dengan selera masyarakat serta warna (bentuk) yang menarik. [1]. Meskipun jajanan saat ini menjadi bagian yang tidak terpisahkan dari masyarakat, ternyata mempunyai resiko terhadap kesehatan. Hal ini disebabkan penggunaan bahan tambah pangan (BTP) oleh pedagang makanan dan minuman.

Bahan tambah pangan (BTP) merupakan senyawa atau campuran yang ditambahkan kedalam makanan dan minuman pada proses pengemasan, pengolahan, dan penyimpanan guna untuk memperbaiki karakter serta meningkatkan kualitas pangan, seperti pengawet, pewarna, pemanis dan pemutih [2]. Bahan tambah pangan (BTP) yang sering digunakan untuk meningkatkan daya tarik makanan dan minuman adalah pewarna. Penggunaan pewarna yang diizinkan dan dilarang untuk makanan diatur dalam SK Mentri Kesehatan RI Nomor 722/MenKes/Per/IX/88 [2].

Winarno, 2004 menyatakan bahwa Tartrazin merupakan pewarna sintetis dari salah satu kelas ozo yang menghasilkan warna kuning dengan gugus bis-azon $\mathrm{R}-\mathrm{N}=\mathrm{N}-\mathrm{R}_{1}-\mathrm{N}=\mathrm{N}-\mathrm{R}_{2}$. Dimana $\mathrm{R}, \mathrm{R}_{1}, \mathrm{R}_{2}$ adalah gugus aromatik. Selain memiliki gugus aromatik tartrazin juga memiliki gugus kromofor yang memiliki ikatan phi $(\pi)$ terkonyugasi. Penggunaan tartrazin dapat memberikan efek yang berbahaya, seperti urtikana (elergi kulit), rhinitis (pilek), asma, purpura(memar pada kulit) dan anafilaksis sistemik (shock).[3]. Struktur zat warna Tartrazin dapat dilihat pada Gambar 1. 
<smiles>O=C(O[Na])c1nn(-c2ccc(S(=O)(=O)O[Na])cc2)c(O)c1/N=N/c1ccc(OS(=O)(=O)[O-])cc1</smiles>

Gambar 1. Struktur Zat Warna Tartrazin.

Penelitian yang dilakukan oleh La Ode Sumarlin menunjukan bahwa beberapa sampel yang diambil didaerah jakarta dan ciputat berupa kerupuk merah dan kuning, es limun botol/orange dan permen merah, positif mengandung pewarna sintetis, akan tetapi masih dalam batas yang telah diizinkan dalam Permenkes RI No 722/Menkes/Per/IX/88[4]. Penelitian yang sama dilakukan oleh Merita dkk (2015) dengan menganalisis pewarna Tartrazin. Hasil penelitian menunjukan bahwa minuman ringan yang beredar di 6 Sekolah Dasar di Bandung positif mengandung tartrazin dengan kadar 13,689-17,689 mg/kg [3]. Penelitian lain tentang zat warna Tartrazin juga dilakukan oleh Wiranti dkk (2009) didapatkan kadar tartrazin pada tidak melebihi $100 \mathrm{ppm}$, akan tetapi menurut KBPOM RI No. 37 Tahun 2013 tentang batas maksimum penggunaan BTP Pewarna ditetapkan bahwan bahan pewarna Tartrazin dalam minuman berbasis perisa tidak berkabonat adalah $70 \mathrm{mg} / \mathrm{Kg}$. [5]

Tujuan dari penelitian ini adalah untuk mengetahui ada tidaknya zat warna Tartrazin dan kadar zat wrna Tartrazin yang terdapat pada jajanan minuman ringan tak berlabel yang dijual oleh pedagang kaki lima didaerah banda aceh dengan menggunakan metoda kromatografi kertas dan Spektrofotometry $\mathrm{UV} / \mathrm{Vis}$.

\section{METODOLOGI PENELITIAN}

\section{Alat}

Bejana Kromatografi, penangas air, neraca analitik, pipa kapiler, kertas saring waltman No.1, benang wool bebas lemak, spektrofotometer $\mathrm{Uv} / \mathrm{V}$ is dan peralatan gelas lainnya.

\section{Bahan}

Sampel (jajanan minuman ringan tak berlabel seperti es lilin, dan es sirup kuning yang dijual pedagang kaki lima didaerah banda aceh), zat warna Tartrazin, metanol, asam asetat $10 \%$, amonia $10 \%$, etil metil keton, aseton dan air.

\section{Pengambilan Sampel}

Pengambilan sampel dilakukan dibeberapa lokasi didaerah Banda aceh, yaitu Darussalam, Ulee Kareng, Lampineng, Lamgugup dan Prada. Sampel diambil dipusat keramaian dimana terdapat banyak banyak pedagang kaki lima. Kegiatan penelitian yang dilakukan antara lain observasi lapangan, pengambilan sampel, analisis (uji) sampel, dan pengolahan (analisis) data. Observasi lapangan dilakukan secara visual dan peneliti terjun langsung kelapangan untuk memeriksa beberapa produk jajanan minuman ringan yang terindikasi menggunakan pewarna makanan. Kemudian, sampel dianalisis secara kualitatif dan kuantitatif dengan metoda kromatografi kertas dan spektrofotometry UV/Vis.

\section{Analisis Sampel}

\section{Kualitatif dengan kromatografi kertas}

Prinsip uji bahan Pewarna Tambahan Makanan (BTP) adalah zat warna dalam contoh makanan/minuman diserap oleh benang wool dalam suasana asam dengan pemanasan kemudian dilakukan kromatografi kertas [6], yaitu : Memasukan $\pm 10 \mathrm{~mL}$ sampel cair atau 10-25 g sampel padatan ke dalam gelas piala $100 \mathrm{~mL}$.. Kemudian diasamkan dengan menambahkan $5 \mathrm{~mL}$ Asam asetat $10 \%$. Selanjutnya masukan dan rendam benang wool ke dalam sampel, panaskan dan diamkan sampai mendidih ( \pm 10 menit). benang wool diambil, dicuci dengan air kemudian dibilas dengan aquades. $25 \mathrm{~mL}$ amoniak $10 \%$ ke dalam benang wool yang telah dibilas tersebut. Panaskan benang wool sampai warna pada benang wool luntur. Benang wool dibuang, larutan diuapkan di atas water bath sampai kering. Residu ditambah beberapa tetes metanol, untuk ditotolkan pada kertas kromatografi yang siap pakai. Kemudian, dieluasi dalam bejana. Eluen yang digunakan berupa etilmetilketon : aseton : air dengan perbandingan 70: 30: 30 sebesar $15 \mathrm{ml}$. Kertas kromatografi diangkat dan dibiarkan mengering. Warna yang terjadi diamati, 
membandingkan $\mathrm{Rf}$ (Retardation factor) antara Rf sampel dan Rf standar.

Perhitungan :

$$
\mathrm{Rf}=\frac{\text { Jarak yang ditempuh komponen }}{\text { Jarak yang ditempuh eluen }}
$$

Kuantitatif dengan spektrofotometer Uv/Vis Pengukuran zat pewarna sintetik pada analisa kuantitatif menggunakan metode Spektrofotometri UV/Vis [7] :

$\underline{\text { Pembuatan larutan standar }}$

Zat warna Tartrazin sebanyak $0,1000 \mathrm{~g}$ dilarutkan dalam $100 \mathrm{~mL}$ akuades untuk mendapatkan larutan induk Tartrazin 1000 $\mathrm{mg} / \mathrm{L}$. Kemudian larutan induk Tartrazin $1000 \mathrm{mg} / \mathrm{L}$ diencerkan menjadi 5 variasi konsentrasi 10, 30, 50, 70 dan $90 \mathrm{mg} / \mathrm{L}$. Metode preparasi sampel pada analisa kuantitatif secara Spektrofotometri UV/Vis menggunakan metode preparasi sampel pada analisa kualitatif (Kromatografi kertas), yaitu : Memasukan $\pm 10 \mathrm{~mL}$ sampel cair atau 10-5 g sampel padatan ke dalam gelas piala 100 ml. Kemudian diasamkan dengan menambahkan $5 \mathrm{ml}$ asam asetat $10 \%$. benang wool dimasukan dan rendam ke dalam sampel. Panaskan dan diamkan sampai mendidih ( \pm 10 menit). Benang wool diambil, dicuci dengan air dan dibilas dengan aquades. $25 \mathrm{ml}$ amoniak $10 \%$ ditambahkan ke dalam benang wool yang telah dibilas tersebut. benang wool dipanaskan sampai warna yang tertarik pada benang wool luntur. Warna yang telah ditarik dari benang wool dan masih larut dalam amoniak kemudian di analisa dengan spektrofotometer UV-Visibel.

\section{HASIL DAN DISKUSI}

\section{Gambaran Umum Lokasi Pengambilan Sampel di Pedagang Kaki Lima}

Sampel yang dijadikan objek penelitian adalah jajanan minuman ringan tak berlabel yang dijual oleh pedagang kaki lima di Banda Aceh. Sampel berupa es lilin dan es sirup berwarna kuning (Gambar 2). Lokasi pengambilan sampel dilakukan pada daerah perkantoran dan sekolah/kampus pada daerah Darussalam, Ulee Kareng, Lampineng,
Lamgugup dan Prada. Daerah tersebut diambil, dikarenakan banyaknya pedagang kaki lima yang menjual minuman ringan dan banyaknya konsumen yang membeli jajanan minuaman ringan tak berlabel seperti anak sekolah, mahasiswa dan pekerja kantor.

\section{Analisis Zat Warna Tartrazin pada Jajanan Minuman Ringan dengan Kromatografi Kertas}

Analisis zat warna Tartrazin pada minuman ringan dilakukan pada beberapa daerah di Banda Aceh. Sampel Jajanan minuman ringan yang dianalisis terdiri dari 5 sampel yang diambil dari pedagang kaki lima. Kemudian, sampel tersebut dianalisis Laboratorium kimia FKIP Unsyiah Banda Aceh. Sampel dilakukan analisis secara kualitaitf dan kuantitatif. Kualitatif menggunakan metoda Kromatografi kertas dan kuantitatif menggunakan metoda spektrofotometri UV/Vis. Dari hasil analisis kualitatif didapat bahwa jajanan minuman ringan yang dijual oleh pedagang kaki lima di daerah Banda Aceh positif menggunakan zat warna Tartrazin. Apabila nilai Rf sampel mendekati atau melebihi nilai Rf standar, maka sampel dikatakan positif menggandung pewarna Tartrazin. Hasil analisis zat warna Tartrazin pada jajanan minuman ringan dengan kromatografi kertas dapat dilihat dari Tabel 1.

Gambar 3 merupakan analisis kualitatif kromatografi kertas yang dilakukan di Laboratorium Kimia FKIP Unsyiah. Dari gambar dapat dilihat laju alir (Rf) standar dan sampel yang dianalisis.

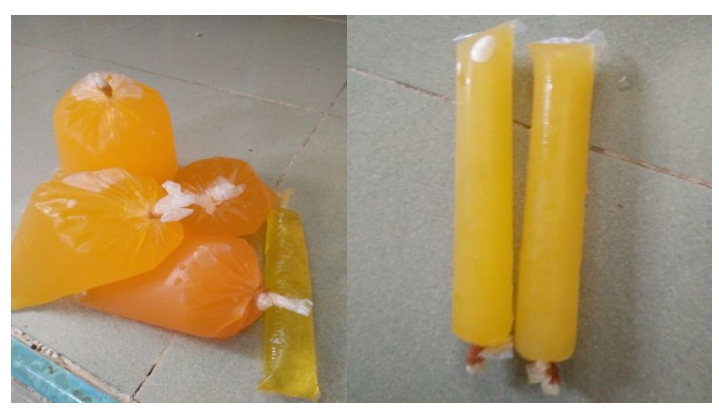

Gambar 2. Sampel Minuman Ringan Tak Berlabel 
Tabel 1. Hasil Analisis Kualitatif Zat Warna Tartrazin dengan Kromatografi Kertas

\begin{tabular}{lllll}
\hline No. & $\begin{array}{l}\text { Nama } \\
\text { Sampel }\end{array}$ & $\begin{array}{l}\text { Rf }_{\text {Standar }} \\
(\mathbf{c m})\end{array}$ & $\begin{array}{l}\text { Rf }_{\text {sampel }} \\
(\mathbf{c m})\end{array}$ & Keterangan \\
\hline 1 & Sampel A & 1,3 & 1 & Positif (+) \\
2 & Sampel B & 2,4 & 4 & Positif (+) \\
3 & Sampel C & 2,6 & 3,3 & Positif (+) \\
4 & Sampel D & 2,9 & 3,0 & Positif (+) \\
5 & Sampel E & 3,5 & 2,6 & Positif $(+)$
\end{tabular}

Keterangan : sampel A = darussalam ; sampel B = Ulee Kareng ; sampel C = Lampineng ; sampel D = Lamgugup; sampel E = Prada

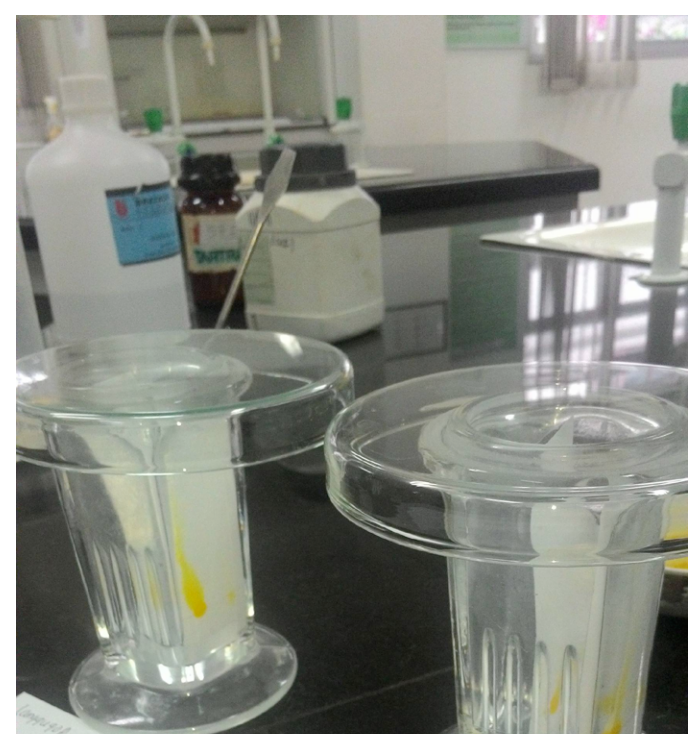

Gambar 3. Analisis kromatografi kertas, menggunakan eluen berupa etilmetilketon : aseton : air dengan perbandingan 70: 30: 30 sebesar $15 \mathrm{~mL}$.

\section{Analisis Zat Warna Tartrazin pada Jajanan Minuman Ringan dengan Spektrofotometri UV/Vis}

Gambar 4 menunjukan serapan maksimum dari standar zat warna Tartrazin pada kosentrasi $10,30,50,70$ dan $90 \mathrm{mg} / \mathrm{L}$ didapatkan persamaan regresi $\mathrm{Y}=0,03717 \mathrm{X}$ $+0,19443$ dengan panjang gelombang $(\lambda)$ $427 \mathrm{~nm}$. Hasil analisis kuantitatif dengan menggunakan spektrofotometer UV/Vis didapat kadar Zat Warna Tartrazin pada Tabel 2.

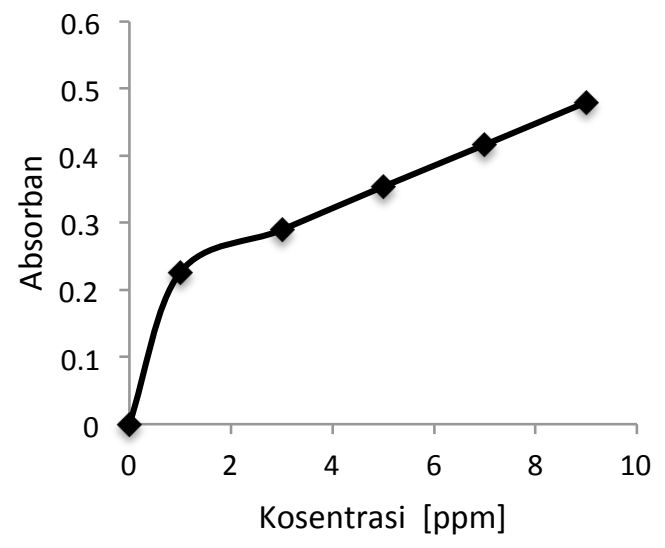

Gambar 4. Kurva Standar Zat Warna Tartrazin.

Analisis zat warna Tartrazin pada jajanan minuman ringan tak berlabel menggunakan metoda Spektrofotometri UV/Vis dengan $\lambda$ $427 \mathrm{~nm}$ ini bertujuan untuk menentukan kadar (kosentrasi) zat warna Tartrazin pada sampel jajanan minuman tak berlabel. Dari tabel 2 terlihat bahwa penggunaan zat warna Tartrazin pada sampel jajanan minuman ringan tak berlabel ini melebihi batas maksimum yang diserap oleh tubuh yaitu sekitar $7,5 \mathrm{mg} / \mathrm{Kg} /$ day berdasarkan ADI (Acceptable Daily Intake)[8-9]. Hal ini berarti, jika sampel dikonsumsi secara terus menerus menyebabkan keracunan bagi tubuh, kerusakan saraf, kelainan sel dan kulit serta kanker usus [10]. 
Tabel 2. Absorban dan kadar zat warna Tartrazin (mg/L)

\begin{tabular}{llll}
\hline No & Nama Sampel & Absorban & Kadar Zat Warna tartrazin (ppm) \\
\hline 1 & Sampel A & 0,234 & 1,06457 \\
2 & Sampel B & 1,242 & 28,1832 \\
3 & Sampel C & 1,704 & 40,6126 \\
4 & Sampel D & 0,779 & 15,7269 \\
5 & Sampel E & 1,270 & 28,9365 \\
\hline
\end{tabular}

\section{KESIMPULAN}

Jajanan minuman ringan tak berlabel yang diambil dari beberapa pedagang kaki lima di daerah banda aceh positif mengandung zat warna Tartrazin dengan kadar yang melebihi batas yang telah ditetapkan ADI (Acceptable Daily Intake) yaitu sekitar $7,5 \mathrm{mg} / \mathrm{Kg} /$ day. Kadar zat warna Tartrazin pada sampel A, B, $\mathrm{C}, \mathrm{D}$ dan $\mathrm{E}$ berturut - turut antara lain 1,$06457 ; 28,1832 ; 40,6126 ; 15,7269$ dan $28,936 \mathrm{mg} / \mathrm{L}$.

\section{DAFTAR PUSTAKA}

1. Santi Novita, Retno Adriayani., tingkat pengetahuan dan sikap pedagang jajanan tentang pemakaian natrium siklamat dan rhodamin B., Jurnal Promkes., Vol 1., No. 2: Hal : 192-200., Desember 2013.

2. Merita wanda mustika, Neti kurniaty, $\mathrm{H}$. Sukanta., Analisis kadar tartrazin dalam minuman ringan tidak berlabel pada sekolah dasar di bandung menggunakan metoda spektrofotometri UV/Vis., Posiding penelitian SpeSIA 2015., Hal : 86-92

3. Anonim., 2002., Tartrazin metals and arsenic prepared at the 28 JECFA (1984)., Published in FNP 31/1 (1984) and in FND 52 (1992) specifications revises at the 59th JECFA)

4. La Ode Sumarlin, Identifikasi Pewarna Sintetis Pada Produk Pangan Yang Beredar, di Jakarta dan Ciputat, Hal : $274-28$.
5. Wiranti Sri Rahayu, Tjiptasurasa, P. Najilah., Analisis zat warna tartrazin pada minuman orson menggunakan metoda spektrofotometri UV/Vis dipasar induk brebes., Pharmacy, Vol. 06 No.01 April 2009 Hal: 94 - 102.

6. Poltekes Bandung, 2002. Penuntun dan Jurnal Praktikum Analisis Bahan Tambahan Makanan. Jurusan Analis Kesehatan Poltekes : Bandung Poltekes Bandung, 2002

7. Depkes RI, 1995. Farmakope Indonesia. Departemen Kesehatan Republik Indonesia Jakarta Depkes RI, 1995

8. Bertha Rusdi, Hilda Aprilia, Wisnu Wardhani., Pengembangan Metoda Analisis Makanan Coklat HT dalam Biskuit Coklat dengan Metoda Kromatografi Kcair Kinerja Tinggi., Posiding penelitian SNaPP 2014.,Sains, teknologi dan Kesehatan., Vol 4., No. 1., Hal : 139 - 146 (2014).

9. Amandeep Kaur and Usha Gupta., Identification ND Determination of Binary Mixtures of Syntetic Dyes With Cr (III) Complexation in Food Stuffs and Pharmaceutical Sample by High Performance Liquid Chromatography., Indian Journal of Pharmaceutical Science \& Research., Volume 4 Nomor 1., 2014 Hal : 49-52.

10. Sedat sayar, Yuksel Ozdemy., Determination of Ponceou 4R adn Tartrazin in Various Food Samples by Derivative Spectrophotometric Metods., J. Of Chemistry., Vol 21., Tahun 1997., Hal 182-187 